\title{
Las adversidades de la docencia online universitaria y las posibilidades ofrecidas por la plataforma Blackboard Collaborate
}

The challenges of online university teaching and the possibilities of the Blackboard Collaborate platform

María José Catalán Chamorro

Profesora Ayudante Doctora

Área de derecho procesal

Universidad de Córdoba (España)

E-mail: d72cachm@uco.es

\begin{abstract}
Resumen: En el presente artículo hemos realizado un repaso por los principales problemas que surgieron en la docencia virtual durante el periodo de confinamiento y cómo podemos reforzarnos para superar la segunda ola de contagios y la docencia semipresencial planificada. Así mismo, hemos intentado explicar de manera pormenorizada las diferentes posibilidades que ofrece la plataforma Blackboard Collaborate para la docencia universitaria a través de la experiencia propia en el grado de Derecho.
\end{abstract}

Palabras clave: Blackboard Collaborate, docencia online, herramientas online para la docencia, problemática en la docencia online. 


\begin{abstract}
In this article we have examined the main problems that arose in virtual teaching during the period of confinement and how we can strengthen ourselves to overcome the second wave of contagion and planned blended learning. We have also tried to explain in detail the different possibilities offered by the Blackboard Collaborate platform for university teaching through our own experience in the degree of Law.
\end{abstract}

Keywords: Blackboard Collaborate, online teaching, online tools for teaching, problems in online teaching.

\title{
1. Introducción
}

Durante los últimos tiempos hemos vivido no solamente situaciones atípicas en nuestras relaciones familiares o con amigos sino también en el ámbito profesional. Todos nos vimos abocados a reinventarnos, a cambiar de color cual camaleón para poder dar lo mejor de nosotros mismos. No obstante, esto supuso un desgaste físico y emocional en la mayoría del personal docente. Estas cuestiones no son exclusivamente nacionales, sino que se han extendido a todo el ámbito educativo mundial tal y como apunta María Francisca Elgueta (2020: 1-3).

Solo un mes más tarde de finalizar nuestra más intensa actividad docente del curso 19/20 volvíamos a darnos de bruces con una segunda ola de contagios. En la primera ola de esta pandemia se optó por una docencia cien por cien online. El problema radicó en que tuvimos que readaptar todos los contenidos, actividades, seminarios, prácticas etc. y evidentemente por el camino se perdió gran parte de la brillantez y el buen hacer del profesorado.

Desgraciadamente, volvíamos a estar en un escenario similar varios meses después. Aunque en esta ocasión se optó por una docencia semipresencial, para de alguna manera romper el bloqueo psicológico y recuperar no solo nuestros hábitos lectivos 
sino también nuestra cotidianeidad. Aunque, debido al alto nivel de contagios, nunca se ha descartado totalmente volver al ámbito online como ha ocurrido puntualmente en algunos centros como la Universidad de Granada ${ }^{1}$ o la Universidad de Oviedo $^{2}$ al inicio del curso 20/21.

Sin embargo, a pesar de saber que volvíamos a estar obligados a dar lo mejor de nosotros a través de una pantalla, ni las universidades ni el gobierno realizaron planes específicos de formación del ámbito online al profesorado. Donde además la brecha digital está intensamente marcada debido a la alta media de edad del profesorado universitario en nuestro país que se sitúa en torno a los 54 años, cifra que por cierto no tiene expectativas de bajar, sino más bien de subir, debido a la falta de becas y contratos para la incorporación de profesorado ${ }^{3}$. Con este escenario era una gran tarea remontar para ofrecer una enseñanza de calidad online durante estos meses de pandemia que aún nos quedan por delante.

En el presente trabajo vamos a intentar dar algunas claves para la mejora de la docencia en el ámbito online en el área de Derecho y algunas sugerencias que sin duda son aplicables a diferentes campos y áreas de la docencia universitaria.

\section{Motivación en tiempos de pandemia}

Durante las primeras clases tras la declaración del estado de alarma y el consiguiente confinamiento total de la población, percibí unas primeras sensaciones de euforia y cierto gusto por parte del alumnado, ya que algunas asignaturas las podían seguir de manera asíncrona -es decir en el horario que ellos estimasen-; era difícil controlar y valorar la presencialidad, debido a que no todos podrían estar teniendo una situación familiarmente fácil o no disponían de los recursos informáticos e internet necesarios; se pospusieron pruebas parciales e incluso hubo

\footnotetext{
1 Ver en: https://elpais.com/educacion/2020-10-13/las-clases-en-la-universidad-de-granada-seran-adistancia-las-proximas-dos-semanas.html, visitado el día 16 de octubre de 2020.

2 Ver en: https://www.rtpa.es/noticias-sociedad:La-Universidad-de-Oviedo-cierra-todos-sus-campusdurante-las-proximas-dos-semanas 111375716427.html, visitado el día 16 de octubre de 2020.

3 Fuente: El País, 10 de enero de 2019, disponible en: https://elpais.com/sociedad/2019/01/09/actualidad/1547044018 002135.html\#: :text=La\%20edad\%2 0media\%20de\%20los,76\%25\%20de\%20su\%20plantilla) visitada el día 27 de agosto de 2020.
} 
parte del profesorado que tardó algunos días o semanas en acceder a este escenario online.

Sin embargo, poco a poco, esta euforia inicial fue decayendo, e incluso pudimos constatar cómo las clases síncronas que se impartían en el horario habitual de clase crecían en número de asistentes, además las preguntas en torno al temario impartido iban aumentando. Y es que, para ellos, comenzó a ser necesario ver al profesor, escuchar su voz, conocer los puntos importantes para tener en cuenta para

el examen, mantener las rutinas de horario, etc. Pero sin duda, el aspecto que más les motivó para implicarse definitivamente en las clases online fue la continuidad del escenario online hasta finalizar el curso, a diferencia del curso 20/21, donde cada universidad planteó un mínimo de tres escenarios entre los que la docencia cambiaría de semipresencial a online dependiendo de la situación sanitaria. Por ello, fue difícil mantener la seguridad jurídica y la motivación del alumnado ante sus dudas sobre el modo y el medio en el que serán evaluados.

Así las cosas, el modo y el medio de evaluación continua diseñado para cada escenario es diferente en cada asignatura, en cada grado y en cada centro, cambiando generalmente el peso porcentual y el ítem evaluado.

\section{Modo de evaluación para mantener la motivación del estudiante}

En cuanto a la evaluación del alumnado durante este periodo de docencia online nos hemos movido en dos variables básicas. Por un lado, el medio que puede ser online $\mathrm{u}$ offline, es decir presencial $\mathrm{y}$, por otro lado, el modo donde ha predominado el peso que se le ha dado a la evaluación continua. De este modo, el docente se presenta como un facilitador que apoya a un estudiante a cargo de la construcción de su propio aprendizaje (Cid et al., 2018:33) y así hacer que la evaluación no sea sinónimo de calificación, sino de ampliación su alcance como un elemento central que orienta el proceso de aprendizaje del estudiante tal y como sentaron Hunt y Chalmers (2013). 
Debido a que nos era imposible captar la atención del estudiante para que este asistiese a las clases online, se subió el peso porcentual sobre la nota final de la asignatura al resto de los instrumentos de evaluación. No obstante, este aumento del porcentaje sobre la calificación final aplicada a instrumentos como prácticas, ejercicios, exposiciones, participaciones en clase, resolución de preguntas en foros, cuestionarios etc. suponía un aumento más que considerable del tiempo que el profesorado invertía en la corrección y evaluación de estos ítems.

Sin embargo, quedó patente que cuando se motiva a un alumno con un rendimiento en forma de calificación responde de manera positiva, incluso si ese trabajo supone un porcentaje irrisorio sobre la calificación final. Les pondré el ejemplo de la puntuación de asistencia a clase en mis asignaturas donde suelen asistir aproximadamente el $60 \%$ del alumnado matriculado cuando en la media de la facultad ronda el 30\% del alumnado matriculado. La fórmula es la siguiente, la asistencia cuenta un $0,75 \%$ sobre la nota final y la participación en las clases un $0,75 \%$, por lo que ambas suman un 1,5\% sobre la calificación final. La puntuación es proporcional al número de asistencias y de participaciones efectivas. De modo que si durante un semestre se ha pasado lista en 20 ocasiones y el alumno ha asistido 10 tendrá un 0,35 sobre los 10 puntos de la calificación final. De igual manera ocurre con las participaciones. Así que, siendo un alumno modélico que asista a clase todos los días y participe en las mismas todos los días podrá aspirar a 1,5 puntos sobre 10 de la nota final. El esfuerzo en este caso es titánico, no solo deben asistir, sino también participar de manera activa en las mismas, sin embargo, la experiencia de implantación de este método ha sido muy positiva en los seis años académicos que ha sido aplicada, aumentando la participación y la asistencia del alumnado de manera importante, de esta manera podemos destacar los siguientes beneficios:

- Una más estrecha y provechosa relación profesor-alumno, dado que permite conocer mejor sus inquietudes, sus dudas y asimilación de la asignatura.

- Una mayor implicación del alumnado en la asignatura. 
- Mejora de la atención del alumnado durante las clases debido a las preguntas que se van lanzando.

- Y un seguimiento y conocimiento generalizado del grupo por parte del profesor.

Son varios los autores que apoyan esta evaluación continua y la implicación de estos ejercicios de evaluación continua como métodos que mejoran empíricamente los resultados del examen final (Sargent y Curcio, 2012). Así, el estudio citado consistente, por un lado, en pruebas de ensayos y respuestas cortas sin calificación y por otro, ejercicios de autorreflexión para evaluar así un conjunto diferente de evaluaciones formativas, tal y como realizo en mis clases, impactó en el rendimiento acumulado de los exámenes finales de los estudiantes (Sargent y Curcio, 2012: 381).

Al inicio del confinamiento y hasta pasadas un par de semanas donde pude recuperar el contacto con la totalidad del grupo y conocer que no existían problemas de conexión o recursos informáticos en el mismo decidí continuar con este mismo criterio de seguir puntuando la asistencia y participación del alumnado.

La experiencia demostró que poco a poco se fueron incorporando cada vez más alumnos a las clases, a pesar de que eran a primera hora de la mañana. Tras cuatro semanas de docencia online, se decidió incrementar el porcentaje de las participaciones al 1,5\% y de la asistencia a un $1 \%$ sobre la calificación final de estos métodos de evaluación, con resultado de un aumento en la asistencia y la participación del grupo a alumnos que incluso no comenzaron la docencia presencial del cuatrimestre en febrero, antes del estado de alarma y se unieron al grupo originario.

Por lo tanto, la motivación del alumnado en el ámbito universitario no depende sólo del modo de dar las clases, el timbre, la voz, las actividades educativas que se realicen en el aula, sino que dependen también en una gran medida de la retribución por el trabajo realizado por parte del alumnado, incluso aunque sea en porcentajes 
muy residuales y cuasi imperceptibles cuando se realizan redondeos de calificaciones para traspasar al acta.

En definitiva, como apunta el experto en neurociencia Francisco Mora, “Aprender, en cualquier circunstancia, siempre es un proceso dependiente de las recompensas y el placer, pero también de los estímulos sociales" . Así las cosas, con este método hemos intentado combinar estos tres factores para un aprendizaje de calidad durante la docencia online, donde no solo hemos trabajado el placer por el aprendizaje y los estímulos sociales a través de la ejemplificación de los contenidos de la asignatura, sino que además se ha aumentado la recompensa del trabajo diario para la mejora del interés en la asignatura y por lo tanto del aprendizaje en su conjunto.

\subsection{La evaluación a través del ámbito online}

Este ítem ha sido uno de los caballos de batalla más temidos por los docentes durante la pandemia. Sin duda, una evaluación del $100 \%$ de una asignatura totalmente a distancia trajo verdaderos quebraderos de cabeza al personal docente.

$\mathrm{Y}$ es que era muy importante el modo de evaluación y redistribuir los pesos porcentuales que asignábamos a cada instrumento de evaluación para establecer un balance para captar la atención, la motivación y la implicación del alumnado y garantizar una asimilación de contenidos básicos para superar la asignatura ${ }^{4}$.

Las herramientas han sido tan variadas como la imaginación del profesorado y los límites de la tecnología nos han permitido. Así las cosas, gracias a la combinación de ambos parámetros y de la búsqueda de buenas prácticas para la docencia online ${ }^{5}$ pudimos salvar el curso a pesar de la pandemia. No obstante, esta tarea fue arduamente complicada para el profesorado más alejado de las nuevas tecnologías y con menor propósito de cambio.

\footnotetext{
${ }^{4}$ Ver más sobre la forma de evaluar la docencia universitaria online en Area Moreira, San Nicolás Santos y Sanabria Mesa (2018: 188-190).

${ }^{5}$ Como es el estudio publicado por Durán Rodríguez y Estay-Nuculcar (2016: 179-180).
} 
En el presente trabajo, vamos a analizar la docencia impartida a través de la plataforma virtual Blackboard Collaborate en el ámbito del grado en Derecho, incluyendo de manera puntual apuntes sobre otro tipo de plataformas o aplicaciones informáticas que nos han permitido enriquecer esta plataforma básica para el profesorado de la Universidad de Córdoba.

\subsection{La docencia online: un mundo de posibilidades}

Sin duda ante cualquier vicisitud el ser humano tiene como mejor opción hacerse más fuerte, como dijo Séneca "No hay árbol recio ni consistente sino aquel que el viento azota con frecuencia”.

\subsubsection{Algunas desventajas de la docencia online}

La frialdad de una pantalla de ordenador aún nos cuesta superarla, aún más cuando estamos desde casa, no sentimos ese calor humano de nuestros alumnos y ellos tampoco perciben el nuestro, aunque tratamos de hacer todo lo posible con nuestra voz y nuestros gestos. No vemos las caras de nuestro alumnado y si las vemos no podemos saber si nos están mirando a nosotros o están leyendo una conversación que tienen en la misma pantalla. Todo esto hace que se cree un clima de inseguridad, de que en ocasiones te sientas solo hablándole a la pantalla del ordenador, aunque aparezcan cuarenta alumnos conectados en ese momento.

\subsubsection{Los derechos de autor del profesorado}

Esta situación se agrava cuando decidimos grabar las clases para posteriormente subirlas a la plataforma, para que el alumnado pueda verlas cuando crea que es más conveniente y pueda retroceder o avanzar en la clase así lo estima. Hay quien afirma que, tras grabar un curso, en años posteriores se podrá prescindir de la labor del profesor y solamente "dándole al play" volverán a tener la explicación sin necesidad de volver a contratar al docente.

Todo ello, sin contar con qué ocurre con los derechos de imagen, de propiedad intelectual o de copyright sobre estos vídeos y materiales que una vez colgados en 
una plataforma pierdes completamente su autoría. Amén de los memes que realiza el alumnado con los videos del profesorado y cuya autoría es muy difícil de probar e investigar debido a la baja peligrosidad de estos, pero a la par son altamente ofensivos para el profesor que lo sufre.

Sin embargo, volviendo a la protección del material docente elaborado por nosotros y distribuido durante este periodo de confinamiento y clases online es importante advertir que es posible protegerlo de manera especial, tal y como podemos ver en la siguiente infografía. 


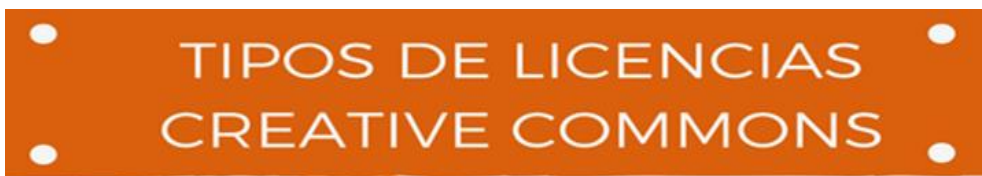

Las licencias CC se basan en la combinación de 4 pictogramas

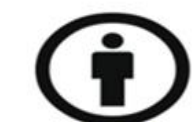

(by)

Atribución

Otorga derecho para

copiar, distribuir, exhibir y representar

la obra, asi como

realizar derivadas siempre y cuando se reconozca y cite la obra original.

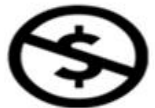

(NC)

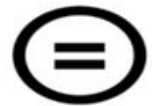

(ND)

No derivadas

Únicamente permite copiar, distribuir. exhibir y representar copias literales de la obra, sin poder producir obras derivadas.

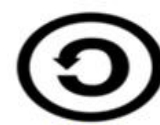

(SA) distribuir, exhibir y represntar la obra, así ocmo realizar derivadas, para fines no comerciales.

$$
\text { igual }
$$

Permite distribuir siempre y cuando sea bajo una licencia idéntica a la de la obra original.

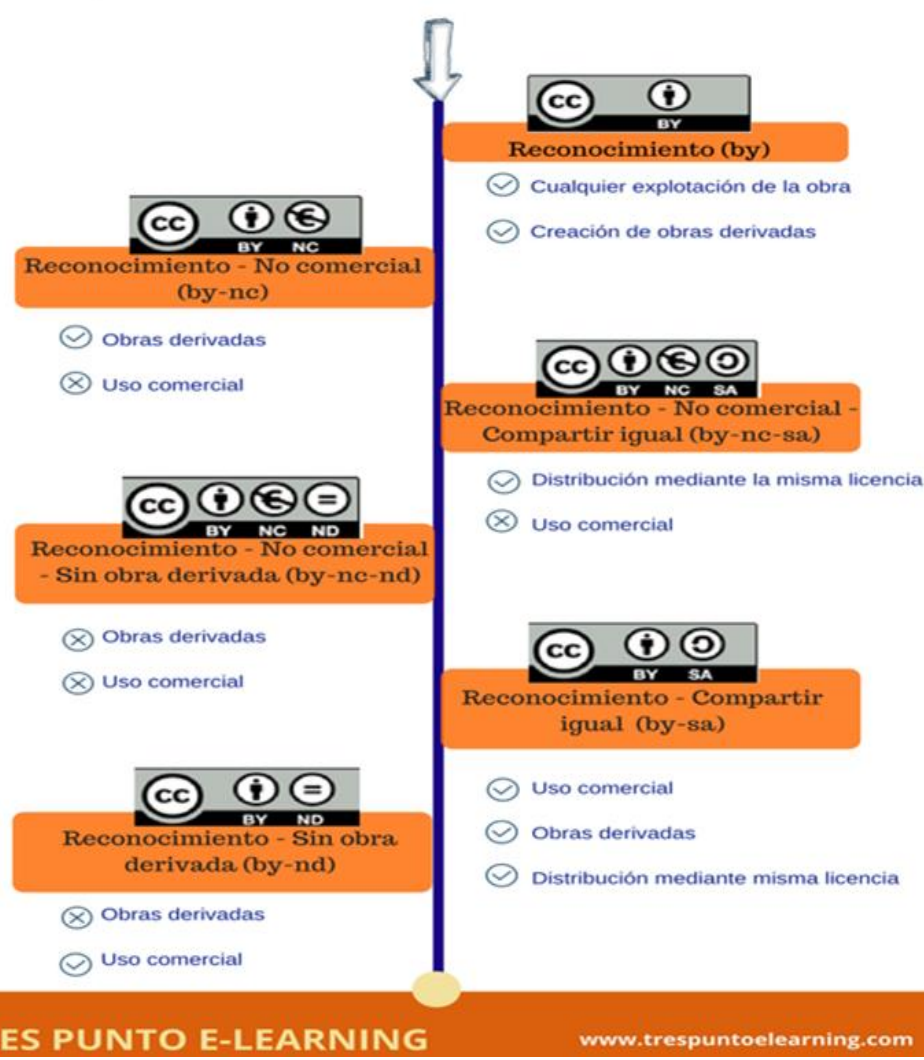

Fuente: TRES PUNTO E-LEARNING

No obstante, es necesario advertir que legalmente no es necesaria la obtención de ningún tipo de licencia específica para proteger nuestros materiales subidos a las plataformas digitales habilitadas por nuestras universidades, ya que la Ley de Propiedad Intelectual es meridianamente clara en este sentido. Así las cosas, en su 
artículo 32.4. $2^{\circ}$ se establece que los alumnos podrán hacer uso de los materiales que se pongan a su disposición a través de las redes internas y cerradas a las que únicamente puedan acceder esos beneficiarios o en el marco de un programa de educación a distancia ofertado por dicho centro docente. En el mismo artículo en el apartado 2, se establece que la propiedad intelectual de estos materiales es un derecho irrenunciable y por lo tanto siempre pertenecerá al autor de estos. Tanto es así que la puesta a disposición del público por terceros -alumnos- de cualquier imagen, obra fotográfica o mera fotografía divulgada en publicaciones periódicas o en sitios Web estará sujeta a autorización del autor y a una compensación equitativa. Es decir, si un alumno pone a disposición del público material subido al aula virtual o una clase emitida para uso exclusivo de esa asignatura y para esos alumnos matriculados, el profesor autor de estos podrá requerir una compensación por los derechos de propiedad intelectual, así como en su caso por daños en caso de que los hubiese por manipulación de los contenidos.

Así las cosas, hay que dejar claros estos términos y condiciones de uso de los materiales docentes al inicio de las clases para evitar malentendidos y potenciales conflictos judiciales entre profesores y alumnos.

\subsubsection{El derecho a la intimidad del domicilio y la propia imagen del alumnado}

Por otro lado, también los alumnos han reivindicado sus derechos respecto de la docencia online. Sobre todo, estas reivindicaciones se han hecho más visibles cuando se les ha exigido la conexión de la cámara ${ }^{6}$ y del micrófono, especialmente durante la duración de los exámenes. Ejemplo de ello fue la demanda admitida a trámite por el Juzgado de lo Contencioso-Administrativo número 3 de Córdoba de un alumno contra la Universidad de Córdoba por "la videovigilancia" en los exámenes a distancia, medida aprobada en el Consejo de Gobierno de la UCO ante las circunstancias provocadas por el coronavirus, al entender dicho alumno que "se

\footnotetext{
6 Ver en profundidad la problemática surgida en torno a las imágenes del alumnado durante la docencia virtual en Arenas Ramiro (2020: 9-15).
} 
viola el derecho a la intimidad del domicilio y que no tiene base legal para hacerse" $"$.

Y es que tal y como relata Ricard Martínez -director de la Cátedra de Privacidad y Transformación Digital Microsoft de la Universitat de Valencia- "resulta obvio que el conjunto de la Universidad española, si graba un examen oral de un estudiante, o bien cuenta con su consentimiento o bien está vulnerando gravemente los derechos fundamentales de la persona examinada y, en consecuencia, poniendo en riesgo no ya los concretos derechos individuales, sino el conjunto de la prueba" ${ }^{\text {. }}$

Estas grabaciones no son más que la garantía a los derechos que el Estatuto del Estudiante Universitario concede al estudiante, ya que de toda prueba evaluable debe de quedar en un soporte físico o electrónico permanente que pueda revisarse en caso de impugnación de la calificación por el alumnado. De este modo, igual que se revisa el examen en papel para conocer si ha existido algún error en la corrección, en el caso de exámenes online se podrán visionar aquellas pruebas para cerciorar la identidad del alumno, para evidenciar algún tipo de sonido, movimiento, o visualización de materiales no permitidos durante el examen o en caso de pruebas orales para revisar el contenido de este ${ }^{9}$.

Y es que la finalidad de la universidad en ningún caso es perpetrar una invasión de la intimidad familiar o domiciliaria, sino solamente dar fe y garantizar que la calificación impuesta a un alumno por el profesor, en el documento público del acta, cumple con las garantías establecidas y no incurre en ningún tipo de prevaricación ${ }^{10}$.

\footnotetext{
7 Disponible en: https://www.europapress.es/andalucia/noticia-admitida-tramite-demanda-contrauniversidad-cordoba-videovigilancia-examenes-distancia-20200515175812.html, visitada el día 31 de agosto de 2020.

${ }^{8}$ Artículo disponible en: https://confilegal.com/20200518-examinarse-en-casa-sobre-la-demanda-delalumno-de-la-uco-por-la-videovigilancia-de-los-examenes-on-line/, visitado el día 31 de agosto de 2020.

${ }^{9}$ Ver este tema en profundidad en Martínez (2020).

${ }^{10}$ Imperativo legal establecido en el artículo 46.3 de la Ley Orgánica 6/2001, de 21 de diciembre, de Universidades que ordena disponer de procedimientos de verificación de los exámenes. BOE núm. 307, de 24 de diciembre de 2001.
} 
Así las cosas, lo que se le pide al alumnado es que eviten que terceras personas se crucen en la línea de la cámara durante las emisiones de clases o exámenes o que se aseguren de instalarse en una estancia que no revele aspectos de la vida privada o familiar, pudiendo establecer un fondo blanco con una pared o sábana que garantice esta privacidad. Por ende, todo aquel que proyecte en su cámara alguno de los aspectos anteriormente indicados renuncia de facto a esta intimidad, no pudiendo posteriormente reivindicarla en un juzgado.

Cuestión diferente es la que surge de aquellos centros donde se le exige al alumnado antes del examen que realicen una grabación de 360 grados del lugar donde va a realizar el examen. Así podríamos ver si hay apuntes colgados de las paredes o en la misma mesa de trabajo donde va a realizar el examen o incluso alguna persona cerca que le pueda realizar alguna indicación, ya que la visión que tenemos normalmente del estudiante es de 45 grados y perdemos mucha información. Durante los exámenes online casi la totalidad del profesorado confiesa haber tenido dudas sobre alumnos que podrían estar copiándose durante los exámenes, sin embargo, en muy pocas ocasiones o casi ninguna hemos podido constatar esta realidad, sino tan solo advertir al estudiante de nuestras sospechas, apelando a su integridad moral para que cejase en su conducta, pero esto no es más que un canto al sol.

Como indica Ricard Martínez la demanda citada al inicio de este apartado "va más allá de la mera invocación de un derecho fundamental, es fiel reflejo de la profunda crisis de valores que atraviesa nuestra sociedad".

\section{La elección de la plataforma perfecta. Blackboard Collaborate}

Seguro que muchos de sus compañeros le han pedido alguna referencia sobre la plataforma que usted usa para realizar sus clases online, así como si le gusta, ventajas o desventajas de esta, etc. Después de analizar varias de estas plataformas y haberlas sufrido en alguna ocasión, se puede decir que no existe una plataforma perfecta, completa e ideal, sino que, igual que cada maestrillo tiene su librillo, cada profesor tendrá su plataforma con la que se siente más cómodo, que le falla menos 
por su sistema operativo, por su formación en ofimática o simplemente porque es la que mejor le ha funcionado durante los meses más duros del confinamiento.

Sin embargo, ahora entra en juego el segundo estadio de las licencias. Y es que durante el confinamiento vimos como múltiples plataformas han prestado una licencia especial a entidades educativas y formativas como "aporte social". Con la aparición de la segunda ola de contagios y el inicio del curso escolar se reanudaron los cobros por las licencias y el profesorado nos vemos limitado por las licencias de las plataformas por las que haya apostado nuestra institución universitaria.

En el presente trabajo analizaremos las posibilidades que nos da la plataforma Blackboard Collaborate para la docencia online. Esta herramienta dispone de dos versiones, la original, que simplemente necesita la instalación de Java o la ultra donde los participantes se unen con una interfaz completamente basada en la web ${ }^{11}$.

Esta herramienta además se puede insertar en plataformas de docencia ya preestablecidas como puede ser Moodle es el caso de la Universidad de Córdoba o cualquier otra aula virtual como por ejemplo la que asiste a la Universidad de Sevilla. El módulo de actividad de herramienta externa permite a los estudiantes interactuar con recursos educativos y actividades alojadas en otros sitios de internet. Por ejemplo, una herramienta externa podría proporcionar acceso a un nuevo tipo de actividad o de materiales educativos de una editorial ajena a la propia plataforma educativa ${ }^{12}$.

Bien, esta herramienta ha sido sobre la que he impartido la mayoría de mis clases online durante el confinamiento. En un primer momento, aposté por ella ya que era la primera herramienta que la Universidad de Córdoba nos proporcionó y posteriormente en comparativa con otras herramientas como CiscoWebex, Zoom o Microsoft Teams ha sido la que más posibilidades me ofrecía a la hora de compartir

\footnotetext{
11 Esta plataforma no es de reciente creación, aunque sí se ha ido perfeccionando con el paso del tiempo, pero sus inicios se remontan a los inicios de siglo. Ver más en Vidal Puga (2004).

${ }^{12}$ Ver otras experiencias de docencia a través de Blackboard en Villalón (2019) o Cabañas Valdiviezo y Ojeda Fernández (2003).
} 
contenidos, pantallas, pestañas, vídeos o incluso poder utilizar una pizarra para poner ejemplos a mis alumnos.

\subsection{Creación y configuración de las sesiones}

Blackboard Collaborate Ultra te permite en primer lugar secuenciar las clases, es decir, bien se pueden crear sesiones esporádicas por ejemplo para una tutoría o programar sesiones para las clases que se tienen previstas para el curso. De este modo, los alumnos al entrar en la plataforma ven a qué hora y qué días están previstas cada una de las sesiones, ya sean de clase o de tutorías. Normalmente, los alumnos que tienen acceso a estas sesiones son aquellos matriculados y previamente cargados por el aula virtual, en nuestro caso Moodle. No obstante, es posible darle acceso a invitados como pueden ser profesores de otras universidades u otras especialidades o alumnos de otros grupos a los que les gustaría recuperar una clase perdida. A los invitados les podremos dar el rol de participante, moderador o presentador (que es el reservado para el profesorado ya que nos permite apagar micrófonos o expulsar de la sala a participantes). Una vez creada la sesión se podrá copiar el enlace de la sesión para hacérsela llegar a los invitados a esta, que podrán acceder simplemente haciendo clic en ese enlace.

Además, se puede permitir la admisión temprana para que el alumnado pueda ir accediendo poco a poco a la sesión minutos antes de la misma. Personalmente suelo optar por una admisión temprana de 15 minutos antes de la sesión, esto repercute positivamente ya que el comienzo de la clase no se suele demorar más de 5 minutos de la hora prevista, ya que hasta que no compruebo que han accedido a la sesión todos los que lo están intentando y que tanto el audio como el vídeo funciona no comienzo a explicar los contenidos previstos para esa sesión.

Cada sesión creada puede ser posteriormente editada en su configuración o incluso eliminarla sin ningún tipo de menoscabo, simplemente haciendo clic junto a la sesión en la parte derecha de la pantalla para desplegar las opciones de la sesión. 
En esta plataforma los ajustes de la sesión son bastante amplios. Por ejemplo, es posible grabar las sesiones, pero solo se podrán descargar si así lo autorizas en los ajustes. También es posible hacer anónimos los mensajes de chat, ya que en

ocasiones podemos creer que de esta manera el alumnado puede tener menos cortedad a preguntar dudas o plantear sugerencias. Como opinión discrepo de este modus operandi en la docencia universitaria, ya que como comentaba supra, prefiero jugar con la motivación y la gratificación del alumnado por estas intervenciones.

En caso de organizar una sesión donde algunos alumnos deban realizar una exposición se le puede dar permiso para compartir video, dibujar en la pizarra y compartir archivos a los participantes. Así mismo es posible darle permiso al alumnado participante para compartir su audio o no, aunque esta opción suele estar marcada de manera predeterminada para que el alumno pueda intervenir en clase a través de voz, y de igual manera ocurre con el chat, que puede ser deshabilitado, aunque siempre son útiles para alumnos que se sientan más cohibidos a la hora de interaccionar por voz.

También es posible habilitar un chat privado con el profesor, para que el resto del alumnado no lo pueda leer, aunque creo que no es una medida positiva, ya que si existe alguna cuestión privada que el alumno quiera comentar al profesor lo podrá hacer vía correo electrónico.

Es posible organizar una sesión en la que se puedan unir más de 250 personas, aunque no es lo habitual en el ámbito académico e igualmente se sitúa un filtro para ocultar blasfemias en los mensajes de chat. Este filtro, debido al ámbito universitario al que está dirigido este trabajo, no creo que deba ser habilitado. En caso de que un alumno tenga una actitud indecorosa o no apropiada durante la emisión de la clase el profesor está habilitado para expulsar al alumno de este o cerrarle el micrófono. 
Otra de las opciones que se puede habilitar es que el alumnado pueda acceder a la sesión a través del teléfono móvil. Es posible que en el momento de la clase al estudiante le falle el ordenador, de esta manera siempre le quedará la opción de seguir la clase a través de su móvil o Tablet.

\subsection{Desarrollo de la clase}

Una vez creada la sesión, llegado el día y la hora de esta todos accederemos a través de la opción unirse a la sesión.

En primer lugar, encontraremos una pequeña prueba de audio y vídeo para que tanto profesorado como alumnado podamos comprobar la efectividad de este, así como advertencias para el caso de que el programa no tenga los permisos suficientes para acceder al micrófono o la cámara de nuestros ordenadores. Para la configuración de estos permisos deberemos ir a la configuración del ordenador y en sus ajustes permitir el acceso expreso de nuestro navegador a la cámara y el vídeo.

Así las cosas, no es muy recomendable que estos permisos permanezcan indefinidamente en el tiempo en nuestros navegadores, ya que pueden ser hackeados y dar lugar a espías en nuestras cámaras y micrófonos. Estos espías llamados RATs (Remote Administration Tools), son soluciones que logran acceder de forma remota a nuestro ordenador y controlar nuestra webcam sin que lo sepamos. Por eso, es recomendable tapar la webcam de nuestros ordenadores con un pequeño trozo de papel y los micrófonos con una simple clavija de auricular ${ }^{13}$.

Una vez que hayamos accedido tenemos tres lugares de control para la gestión de la sesión -zona inferior de la pantalla, parte izquierda y parte derecha de la pantalla-.

\subsection{Iconos visibles y sus funciones}

Comencemos por la más sencilla, los comandos que aparecen en la parte inferior de nuestra pantalla donde encontraremos cuatro iconos. De izquierda a derecha

13 Ver más en: https://www.xataka.com/seguridad/deberias-tapar-la-camara-y-el-microfono-de-tuportatil-hasta-zuckerberg-lo-hace, visitado el día 1 de septiembre de 2020. 
encontraremos, en primer lugar, una figura con silueta de persona que nos indicará con un tic en verde nuestra conexión efectiva. Si hacemos clic en la figura nos aparecerá nuestro nombre, nuestro rol (en caso de ser profesor aparecerá moderador). Desde este punto se nos permite mostrarnos ausentes, en caso de recibir una llamada o tener que pausar la clase por algún motivo excepcional, y más abajo permite indicar nuestro estado anímico -feliz, triste, sorprendido, confundido, más rápido, más lento, de acuerdo o en desacuerdo- con lo que se está diciendo en la clase. Esta opción también la tienen los alumnos, pero este estado será momentáneo ya que solo dura 30 segundos. Además, desde este punto se puede cerrar sesión, lo que indica que nos salimos de la clase, aunque podremos volver a entrar si así lo deseamos durante el horario planificado para la sesión previamente.

Al lado de esta figura encontraremos los tres iconos más importantes durante nuestras retransmisiones. De izquierda a derecha encontramos en primer lugar el micrófono que si está tachado por una línea nos indica que nuestro micrófono está desactivado. Lo podemos desactivar si por ejemplo tenemos una llamada urgente y no queremos que los alumnos la escuchen o queremos silenciar un momento nuestra retransmisión. Esto no quita que si tenemos la cámara encendida sí puedan estar viéndonos. Al inicio de la sesión nos harán una pequeña prueba de audio en caso de que tengamos nuestro micrófono apagado. Una vez iniciada la sesión, la forma de saber que el alumnado le está escuchando es que al hablar veremos como el icono del micrófono -no tachado- se colorea de verde durante nuestra locución. En caso de que nuestro micrófono aparezca tachado para activarlo solamente debemos hacer clic sobre este icono, y de igual manera para desactivarlo.

A la derecha del icono del micrófono veremos el icono de la cámara. De igual manera que el micrófono si aparece tachado con una línea significa que nuestra cámara está desconectada y por lo tanto nuestro alumnado no nos está viendo. Si la cámara aparece sin tachar y en color azul significa que nos están viendo y podremos ver la imagen que vamos a retransmitir, ya que al activarla se inicia una vista previa -como indicábamos anteriormente- para que volvamos a confirmar si queremos compartir vídeo con la imagen que tenemos en ese momento. En caso 
contrario podemos cancelar y no llegar a compartir la imagen si así lo estimamos conveniente.

Y finalmente, en cuarto lugar, encontramos una figura con el brazo levantado hacia arriba. Este se pulsa cuando un asistente quiere pedir el turno de palabra. Normalmente, este icono es utilizado por el profesorado en caso de que un alumno se encuentre realizando una presentación y quiera intervenir de esta manera. Sin embargo, este icono será utilizado con mucha asiduidad por el alumnado. Una vez que un alumno lo pulse, al profesor le aparecerá un mensaje en la esquina superior derecha para avisarle de quien ha solicitado la palabra junto con un timbre de aviso. De esta manera, el profesor cuando lo crea conveniente le dará la palabra al alumno para que plantee la duda, pregunta o sugerencia que tenga respecto del contenido que se está explicando en ese mismo momento.

En la esquina superior izquierda de la pantalla aparecen tres pequeñas líneas que si hacemos clic sobre ellas nos despliega diversas opciones que pueden ser muy útiles para resolver dudas a la hora de la utilización de Blackboard Collaborate.

En primer lugar, se ofrece la posibilidad de grabar la sesión. Esta sesión podrá ser revisualizada por los alumnos o el profesor en otro momento y solo podrá ser descargada en los propios ordenadores si así lo ha previsto el profesor en la configuración de la sesión.

Para visualizar sesiones grabadas en la página principal donde aparecen todas las sesiones próximas en la esquina superior izquierda existen tres líneas blancas que al hacer clic sobre ellas se abre un desplegable donde podremos elegir entre visualizar las sesiones o las grabaciones.

En segundo lugar, se ofrece la posibilidad de vincular su audio al teléfono, esto se utiliza para casos donde el ordenador utilizado no dispone de micrófono o altavoces o estos fallan. De este modo es posible que desde su dispositivo móvil pueda escuchar o ser escuchado a falta de micrófono o altavoces en el ordenador. Para ello, se le facilita un número de teléfono y un pin específico para cada usuario. 
En tercer lugar, aparece la opción reportar un problema. Al clicar sobre este en la parte derecha de la pantalla se abrirá un cuadro donde se debe marcar una de las cuatro problemáticas más usuales donde encontramos: no puedo escuchar a los demás, los demás no pueden escucharme, no puedo ver a los demás o los demás no pueden verme. Así mismo se podrá describir un problema concreto o diferente a los preestablecidos. Una vez terminado se le dará al botón de enviar.

En cuarto lugar, encontramos un apartado sobre informarme acerca de Collaborate, en este apartado podremos hacer un breve repaso por toda la plataforma que nos ayuda a conocer algunos de los comandos que estamos describiendo, pero a un nivel muy básico. Si queremos conocer más en profundidad la plataforma deberemos ir al quinto apartado de la esquina superior izquierda donde aparece "Ayuda de Blackboard Collaborate"14. Este apartado le redirige a una web externa en la que, a modo de glosario, se explica paso a paso toda la información sobre la plataforma. Sin embargo, esta información no es fácilmente entendible y pueden tener problemas para encontrar exactamente la información que necesitas.

Finalmente encontramos información sobre la política de privacidad ${ }^{15}$, esto es el detalle respecto del uso y la protección de datos de los usuarios de la plataforma así como el uso de cookies en el ordenador donde se use este programa, de las que en un simple vistazo no se atisba un gran abuso de la información depositada en esta plataforma, por lo que podemos calificarla de segura, si analizamos otras políticas de privacidad de plataformas como Zoom, Cisco Webex, Skype o Microsoft Teams. Sin embargo, no han sido estudiadas en profundidad por lo que tampoco podemos afirmar que es $100 \%$ segura. No obstante, no hemos encontrado noticias sobre incidencias de seguridad de esta plataforma.

La última de las opciones que encontramos en esta esquina superior izquierda es la posibilidad de cerrar la sesión de forma que solo nosotros saldremos de la clase, y

\footnotetext{
14 Ver más en: https://help.blackboard.com/eses/Collaborate/Ultra/Moderator?utm source=Ultra\&utm medium=Collaborate\&utm campaign=Prod uct_link\&utm_content=Moderator, visitada el día 2 de septiembre de 2020.

15 Ver más en: https://help.blackboard.com/es-es/Privacy Statement, visitada el día 3 de septiembre de 2020 .
} 
la sesión permanecerá abierta durante el tiempo que la hayamos programado, pudiendo volver a entrar si así lo estimamos conveniente.

$\mathrm{Y}$, en tercer lugar, encontramos el panel de Collaborate, desde donde vamos a dirigir el grueso de nuestra clase.

\subsection{Las posibilidades del Panel Collaborate}

Este panel aparece en la esquina inferior derecha con un botón de color púrpura que al pulsarlo se abrirá el panel Collaborate en todo el lateral derecho de la pantalla. Así las cosas, en la parte inferior del mismo disponemos de cuatro iconos.

\subsubsection{Chat}

Un primer icono en forma de globo de diálogo desde donde el profesor y los alumnos se podrán comunicar a través de mensajes de chat. El chat se puede utilizar tanto de forma privada como de manera pública. De manera privada puedes escribirle un mensaje a un alumno en concreto y de manera pública puedes escribir para que todos reciban ese mensaje. Normalmente, aunque sea un mensaje para un alumno porque por ejemplo esté haciendo demasiado ruido en su micrófono o por cualquier circunstancia que esté ralentizando el normal desarrollo de la clase, lo suelo hacer de manera pública, ya que a veces este alumno no lo ve, pero el resto de los compañeros se lo pueden hacer saber vía WhatsApp o telefónica.

Además, este chat permite enviar al alumnado enlaces a webs que pueden ser visitadas, así como hacer uso de emoticonos que pueden ayudar a captar la atención del estudiantado.

\subsubsection{Asistentes}

El segundo icono, en forma de dos figuras con siluetas de personas se puede ver el número de participantes. Al hacer clic sobre estos se pueden visualizar los nombres de cada participante separados por los roles asignados -participante, moderador y presentador si lo hay-. 
Así las cosas, se puede ver si tienen conectado el micrófono y la cámara porque aparecen unos pequeños símbolos en el lado izquierdo del nombre de estos. Y además aparecerá una figura con la mano levantada al lado de sus nombres en caso de que estos hayan pedido la palabra. El profesor podrá bajarles la mano una vez contestada la pregunta haciendo clic en la figura del alumno. También es posible visualizar la calidad de la conexión de cada participante en la parte izquierda de la pantalla haciendo clic en el icono representado por una especie de pila con líneas dentro de esta.

A la derecha de este icono aparece otro representado con un círculo y tres puntos dentro del mismo. Al hacer clic sobre él, se despliega un listado de acciones que podemos hacer respecto de ese participante estudiante en concreto.

En primer lugar, aparece un globo de diálogo para abrir un chat privado con ese alumno. Y posteriormente se suceden tres opciones para cambiar el rol del alumno participante como puede ser convertir en moderador, en presentador o en subtitulador. De este modo, si el alumno tiene que hacer una presentación de un tema o quiere compartir algún contenido con el resto de la clase lo podrá hacer siempre que le demos permiso como presentador o moderador. Este permiso se puede quitar al finalizar la intervención. No obstante, este permiso se eliminará para la siguiente sesión o si este sale de esta.

Finalmente, como última opción nos permite eliminar de la sesión a ese participante que bien porque no deba estar en esta sesión o bien porque esté resultando incómodo para la misma podamos expulsarlo, normalmente tras advertirle de que si no cesa en su comportamiento nos veremos obligados a su expulsión de la sala, de la misma manera que haríamos en una clase presencial.

\subsubsection{Compartir contenido}

Uno de los puntos más importantes de esta aplicación es posiblemente este apartado tercero del panel Collaborate donde al hacer clic sobre el tercer icono en forma de cuadrado con una flecha que sale hacia el exterior accedemos a las posibilidades de 
compartir contenido para apoyar nuestra sesión con los elementos necesarios para la realización de una clase real y efectiva.

Personalmente, fueron estas posibilidades las que me hicieron optar para la mayoría de mis sesiones con el alumnado por esta plataforma.

Divide este apartado en tres subapartados, un contenido primario, un contenido secundario e interactuar.

\section{a. Pizarra}

En primer lugar, en el contenido primario tenemos la opción de Compartir pizarra en blanco, una de mis favoritas, ya que una de las mayores mermas que tenemos a la hora de realizar la docencia online es el déficit del uso de la pizarra para realizar esquemas o diagramas necesarios para hacer entender un ejemplo, un concepto o un caso concreto. Esta pizarra es retransmitida a tiempo real con nuestros alumnos y nos permite dibujar con un lápiz trazo libre, agregar texto y agregar formas geométricas básicas -rectángulo, elipse y línea-, además de poder seleccionar el color en el que realizamos cada una de las acciones descritas. Además, se puede utilizar un borrador, un puntero para indicar lo que hemos dibujado y la opción de seleccionar parte de nuestro dibujo y moverlo a un lado diferente de la pizarra.

Para dejar de compartir la visualización de la pizarra tan solo tendremos que darle al icono redondo con un cuadrado en su interior que aparece a la derecha del comando compartir pizarra en blanco.

Esta herramienta es única en todas las aplicaciones que he utilizado para la docencia en el ámbito universitario y permite expresar más allá de la simple voz que utilizamos en el resto de las aplicaciones.

b. Compartir aplicación o pantalla

En segundo lugar, aparece la opción de compartir aplicación/pantalla, por ello debemos distinguir entre una aplicación y nuestra pantalla. Cuando compartimos nuestra pantalla, nuestros alumnos verán la totalidad de nuestra pantalla, es decir, 
todo lo que nosotros estamos viendo en ese momento, incluyendo el reloj o las aplicaciones que tenemos instaladas en nuestro ordenador. Esto es lo que normalmente nos deja compartir las aplicaciones.

Pero en el caso de Blackboard Collaborate además nos permite compartir solamente una aplicación o compartir solamente una pestaña de nuestro navegador. Así las cosas, si por ejemplo queremos compartir con nuestro alumnado nuestra presentación PowerPoint, tan solo tendremos que indicar compartir pantalla, ventana de la aplicación y seleccionar el PowerPoint previamente abierto. Puede ser una ventana de la aplicación PowerPoint, un documento de Word, un pdf, un vídeo o una fotografía. Para ello, como indicaba anteriormente es necesario que previamente hayamos abierto esta aplicación, aunque la tengamos minimizada o abierta en segundo plano en nuestro ordenador para poder compartirla en el momento de la clase.

De la misma manera procederemos si lo que queremos que visualicen nuestros alumnos es una página web situada en una pestaña que previamente hemos abierto en nuestro navegador de internet. Hacemos clic en compartir una pestaña de Chrome, y marcaremos la pestaña concreta que queremos compartir. Si además queremos compartir el audio que nos ofrece una web determinada deberemos hacer clic en el cuadro situado a la izquierda de la subpantalla de compartir. De lo contrario, si lo que estamos proyectando desde una web es un vídeo nuestro alumnado no lo escuchará, salvo que pongamos nuestros altavoces y lo escuchen por nuestro micrófono.

Así las cosas, haremos clic sobre la aplicación o la pestaña de nuestro navegador de internet que queremos compartir con nuestro alumnado y haremos clic sobre el botón compartir que se sitúa en la esquina derecha de la subpantalla de compartir que se nos ha abierto.

Durante una sesión nos podremos mover por la plataforma compartiendo la pizarra en blanco, compartiendo la pantalla, una aplicación o pestaña de esta indistintamente, sin necesidad de cerrar la sesión durante estos cambios. 
Si bien es cierto, que por precaución y dado que es posible que cometamos errores a la hora de realizar estas acciones, es recomendable que nos aseguremos, durante las sesiones con estudiantes, de intentar tener cerradas aquellas aplicaciones o webs de internet que comprometan nuestra vida privada o la intimidad personal como pueden ser webs o aplicaciones bancarias, fotografías familiares, emails o whatsapps con amigos, etc. para evitar situaciones embarazosas con nuestro alumnado.

\section{c. Compartir cámara}

La opción compartir cámara aparece nuevamente aquí en el panel Collaborate además de en la parte inferior de la pantalla como antes comentamos debido a que cuando hacemos clic para dejar de compartir la pizarra en blanco o la aplicación o web que hemos querido enseñar a nuestros alumnos no volverán a ver nuestra imagen de la cámara hasta que no la activemos de nuevo, reanudando así la retransmisión de nuestra imagen.

\section{d. Compartir archivos}

Como última de las herramientas del contenido primario del panel Collaborate encontramos el apartado compartir archivos, desde el cual podemos enviar archivos a tiempo real a todos los participantes para que lo reciban en el instante.

De esta manera, no se permite a los participantes que se descarguen este archivo en sus terminales, pero sí se les permite moverse a lo largo de la página como ellos estimen, aunque no podrán pasar la página en caso de tratarse de varias páginas, sino que esto queda reservado al profesor moderador. Este contenido puede tener formato pdf, imágenes jpg o PowerPoint pudiendo bien arrastrarlos desde la carpeta al espacio de la pantalla habilitado a tal fin o haciendo clic en agregar archivos y buscando el documento que queremos compartir con el alumnado.

Una vez que consideremos que el alumnado ha visto el documento o la imagen que queríamos proyectarles, clicaremos sobre el icono en forma de círculo al lado del documento para dejarlo de compartir. Posteriormente podremos eliminar el archivo 
o cambiarle el nombre si así lo deseamos. No obstante, al cerrar la sesión el archivo desaparecerá.

Esta herramienta tiene una utilidad relativamente limitada al impedir que el alumnado pueda descargarse los archivos y puedan moverse a lo largo de todo el documento. De modo que puede ser utilizada para mostrar aspectos concretos de una sentencia, una imagen o algún párrafo concreto sobre el que se les quiera ilustrar.

\section{e. Sondeos}

Para interactuar con el alumnado, la herramienta de contenido secundario sondeos permite al profesor lanzar preguntas para recibir el feedback del alumnado. Bien puede ser sobre el temario o sobre la logística de las clases.

En esta aplicación se permiten dos tipos de sondeos: de opción múltiple donde se introducirá el enunciado de una pregunta y se agregarán las diferentes opciones a, b, c-... que se estimen convenientes a través de agregar opción- y clicando sobre el botón de inicio para iniciar el sondeo. Además, se puede actualizar añadiendo alguna opción más una vez ya iniciado el sondeo.

Del mismo modo, podemos iniciar un sondeo con una pregunta que tenga una respuesta simplemente afirmativa o negativa. Sin posibilidad de ser justificada en el sondeo por el alumnado.

Una vez iniciado el sondeo las respuestas del alumnado serán anónimas, aunque sí se podrán visualizar en números absolutos.

Este tipo de sondeos permite al profesorado captar la atención del alumnado y tomar un poco la temperatura del grupo para conocer el grado de escucha que están prestando a la clase. A la par de servir para contar alguna anécdota o permitir que el alumnado intervenga en la sesión a fin de justificar sus respuestas.

Una vez finalizado el sondeo deberemos hacer clic sobre el icono del círculo con el cuadrado interior para poner fin y seguir con la sesión. 


\section{f. Grupos de trabajo}

Esta última herramienta que nos permite compartir con nuestro alumnado es un poco difícil de gestionar.

Lo que permite es la creación de grupos de trabajo que cuentan con su propio audio, video, pizarra, uso compartido de aplicaciones y chat privados. Esto hace que cualquier colaboración que se lleve a cabo en un grupo es independiente de la Sala principal (y otros grupos).

En primer lugar, deberemos elegir entre asignar los grupos aleatoriamente, donde el programa asignará un grupo a cada alumno o puedes personalizar los grupos arrastrando cada nombre de cada alumno a un grupo concreto. Además, se puede utilizar la opción de permitir que los asistentes cambien los grupos, de modo que se podrían mover por afinidad entre los estudiantes. Se pueden crear tantos grupos como el docente requiera en cada caso y una vez estén configurados los grupos se le da a iniciar.

Los asistentes de cada grupo podrán trabajar entre ellos y no serán escuchados ni leídos por el resto de los asistentes de otros grupos. Una vez que queramos finalizar la actividad, simplemente le tendremos que dar al icono del círculo con el cuadrado dentro para finalizar el grupo de trabajo.

Finalmente encontramos un icono con una rueda dentada o de engranaje que simboliza los ajustes personales del moderador profesor sobre el audio o el video de la sesión. Las formas en las que queremos que se nos notifique que alguien se ha unido o ha abandonado el grupo, si alguien publica un mensaje de chat o si un alumno levanta la mano.

A continuación, encontramos los ajustes de la sesión como compartir audio, video, mensajes de chat o dibujar en la pizarra y compartir archivos que por defecto están marcados. Y finalmente aparece un icono en forma de globo de diálogo desde donde podemos reportar un problema surgido durante la sesión con la misma 
fórmula que vimos anteriormente para la barra lateral izquierda que se despliega de la esquina superior izquierda de la pantalla.

De esta manera finalizamos nuestro tour por todas las herramientas que Blackboard Collaborate pone a nuestra disposición para facilitar la docencia online en el ámbito universitario y que han servido de manera muy provechosa en el Grado en Derecho durante los meses más duros de la pandemia.

\section{Referencias bibliográficas}

AREA MOREIRA M.; SAN NICOLÁS SANTOS M. B.; SANABRIA MESA A. L., "Las aulas virtuales en la docencia de una universidad presencial: la visión del alumnado", RIED. Revista Iberoamericana de Educación a Distancia 21(2), 2018, pp. 188-190.

ARENAS RAMIRO, M., "Cámaras e imágenes personales en el proceso de aprendizaje universitario", Revista de Educación y Derecho, núm. 22, 2020, pp. 915.

CABAÑAS VALDIVIEZO, J.E.; OJEDA FERNÁNDEZ, Y.M., Aulas Virtuales Como Herramienta De Apoyo En La Educación De La Universidad Nacional Mayor De San Marcos, Lima, 2003, Disponible en: https://sisbib.unmsm.edu.pe/Bibvirtual/tesis/Ingenie/Caba\%C3\%B1as_V_J/cap1.ht

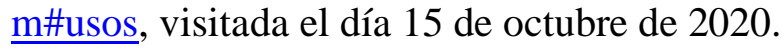

CID DROPPELMANN, MOYA FIGUEROA, TOLEDO ZÚÑIGA y QUINTANO MÉNDEZ, "Experiencia de evaluación continua en cursos del ciclo inicial en la carrera de derecho de la UCT", Revista Pedagogía Universitaria y Didáctica Del Derecho, Vol. 5 Núm. 2, 2018.pp. 31-49.

DURÁN RODRÍGUEZ, R. y ESTAY-NICULCAR, C.A., "Las buenas prácticas docentes en la educación virtual universitaria", REDU. Revista de Docencia Universitaria, 14(2), 2016, pp. 179-180. 
ELGUETA ROSAS, M.F., “Desafíos de la educación jurídica latinoamericana en tiempos de pandemia”, Revista Pedagogía Universitaria y Didáctica del Derecho, Vol. 7, Núm. 1. 2020, pp. 1-3.

HUNT, L. y CHALMERS D., University Teaching in Focus: A learning-centred approach, Routledge, Nueva York, 2013.

MARTÍNEZ MARTÍNEZ, R., "Tecnología de verificación de identidad y control en exámenes online", Revista de Educación y Derecho, Núm. 22 (2020).

SARGENT S., C. y CURCIO A. A., "Empirical Evidence That Formative Assessments Improve Final Exams”, Journal of Legal Education 61 (3), 2012, pp. $379-405$.

VIDAL PUGA, M.P., “Uso Y Evaluación De La Plataforma De EnseñanzaAprendizaje Virtual «Blackboard»", Píxel-Bit. Revista de Medios y Educación, $\mathrm{N}^{\circ}$ 24 Julio 2004 pp. 89-100.

VILLALON R., GARCIA BARRERA M. L.A., "Valoración y uso de la plataforma Blackboard Collaborate en una universidad a distancia", Digital Education Review, Núm. 35, June 2019. 